\title{
Lessons From Italy: A Good Pension System Needs an Effective Broader Social Policy Framework
}

In many countries, pension arrangements are still at the core of the policy debate. Funded and pay-as-you-go (PAYG) schemes are both in question. In Chile, people are taking to the streets to change the funded scheme, which is blamed for low retirement incomes and high fees. In France, citizens are also protesting the government reform of the PAYG system and its attempt to reduce occupational disparities.

The need to tinker with social security is prompted by three main interconnected factors. ${ }^{1}$ First, the ageing of the population will increase public expenditure for transfers and services of the elderly, with pensions bearing much of the pressure.

Second, pension rules are often not neutral with respect to retirement decisions and encourage early retirement. The adverse effects of pension rules on labour market participation rates are particularly worrisome in view of the ageing process.

Third, while the economic conditions of the elderly have improved in relative terms and their incomes have largely been spared by the recent economic crisis, low-paid and fixed-term contract workers increasingly experience poverty, marginalisation and economic insecurity (OECD, 2019a). High pension spending reduces the resources available for protecting these social groups.

(C) The Author(s) 2020. Open Access: This article is distributed under the terms of the Creative Commons Attribution 4.0 International License (https://creativecommons.org/licenses/by/4.0/).

Open Access funding provided by ZBW - Leibniz Information Centre for Economics.

* The opinions expressed in this paper are those of the authors and do not necessarily reflect those of the Banca d'Italia. We are grateful to Fabrizio Balassone, Ilaria De Angelis and Pasquale Recchia for their useful comments.

1 See Francese et al. (2005) and Pino and Yermo (2010) for comparative surveys of earlier reform efforts. Barr and Diamond (2008) provide a thorough and authoritative analysis of the economics of pension reforms.

Daniele Franco, Bank of Italy, Rome, Italy.

Pietro Tommasino, Bank of Italy, Rome, Italy.
Italy, which is sometimes considered a laggard in terms of social and economic reforms, can boast a pension system that is, by and large, functioning sufficiently well in terms of ensuring an adequate purchasing power to retirees and a financially sustainable outlook in the long term, even when taking into account adverse demographic developments. This notwithstanding, the system is currently under attack from different angles. Some of the criticism is technical and can be addressed without changing the nature of the system. Other critical comments address a more fundamental level, but are basically related to the shortcomings of other social protection instruments (e.g. active labour market policies and poverty alleviation schemes).

Technical criticisms are mostly well taken but, in the current juncture, risk being counterproductive. With their quest for perfection, these criticisms may distract from what appears to be the largest looming danger, namely that the system as it is now - not perfect, but relatively satisfactory - could be jeopardised by short-term political considerations.

The Italian pension system: Where we are and how we got here

The need to overhaul the Italian pension system has been on the agenda since the late 1970s, but the reform process only began in 1992 due to pressure from the exchange rate crisis and an urgent need to curb the doubledigit public finance deficit.

Italy's pension system had three main problems: high and rising expenditure, inadequate labour market incentives and chaotic distributional effects.

Pension expenditure, which had increased from $5 \%$ of GDP in 1960 to about 15\% in 1992, was expected to increase further to close to $25 \%$ of GDP by 2030 (Franco and Marino, 2002). The contribution rate needed to cover private sector employees' benefits was set to increase from $44 \%$ in 1995 to $60 \%$ in 2025 . The existing pension formula, eligibility conditions and indexation rules granted rates of return that were considerably higher than the rate of growth of the social security tax base.

The lack of any direct link between the size of the pension benefit and the age of retirement was an incentive to retire as early as possible. In addition, the segmentation of the 
pension system into several separate pension schemes, each one operating with its own rules, hampered the mobility of workers both between and within the public and private sectors.

There were also equity reasons for the reforms. The rate of return on contributions was extremely uneven across different groups of workers. It was usually higher for individuals with earnings rising towards the end of their careers.

\section{The 1992 reform}

The 1992 reform primarily addressed the sustainability issue, cancelling overnight about one-quarter of existing public pension liabilities (Franco, 2002).

The age of retirement in the private sector was raised gradually from 55 to 60 years of age for women and from 60 to 65 for men. The reference period for calculating pensionable earnings gradually increased from five to ten years and, for younger workers, to the entire span of the working life. The minimum number of years of contributions for entitlement to a pension was raised from 15 to 20. The minimum number of years of contributions required for public sector employees to receive a seniority pension was raised gradually to 35 (the requirement already in effect for the private sector). The pension benefits indexation was changed from wages to prices.

\section{The 1995 reform}

Traditional textbook discussions of pension policy usually begin with the comparison of PAYG and funded systems. In PAYG systems, current contributors pay current pensioners; in funded systems, pensions are paid out of a fund that has been built up over several years.

However, PAYG schemes can borrow some of the features of investment-based schemes, especially with regard to the intergenerational distribution of macroeconomic and demographic risks. This is the approach adopted in notional defined contribution (NDC) plans (Holzmann and Palmer, 2005; Holzmann et al., 2012; Holzmann et al., 2020). The financing of the system remains PAYG but the formula that translates the contributions into benefits weighs each year's contribution by a discount factor that is proportional to the medium-run growth of the wage base - as if the contributions had been invested at a compound interest rate equal to the rate of growth. At retirement, the actualised sum of contributions is divided by a factor that reflects life expectancy and the age of the individual, as if the person were using his or her notional wealth to buy an annuity on the insurance market. Social security administrators keep track of cumulated contribu- tions and can communicate this amount to the worker, as if the person had an actual account.

As a consequence, NDC systems can mimic the microeconomic incentives of an investment-based plan without imposing the strains of the transition that would be needed if a PAYG system were to be transformed into a funded system. From a macroeconomic viewpoint, NDC systems can be designed to adjust automatically in order to respond to changes in exogenous variables, thereby reducing the need for discretionary rule changes. Personal accounts can give workers a clearer perception of their pension situation. Transparent accrual rules increase the information available for efficient decision-making during working life. Finally, giving people personal accounts makes it easier to move across jobs and sectors.

The 1995 reform focused on incentives and distribution (the two remaining problems, after the explosive expenditure outlook was curbed by the 1992 reform). Italy switched to an NDC pension system, although with a rather long transition period. ${ }^{2}$ Its design was a big step forward in both areas, as Italy moved towards homogeneous retirement rules and uniform rates of return. In the new NDC system, workers could choose to retire between 57 and 65 years of age, provided the pension benefit amounted at least to 1.5 times the 'social pension' (pensione sociale $)^{3}$ and the number of contribution years was at least five. The supplementation of old-age pensions up to a pre-set minimum level (integrazione al minimo) was abolished. Seniority pensions were retained, but the eligibility requirements were tightened.

The reform also introduced greater incentives for the development of supplementary pension schemes, with the idea that a shift to a multi-pillar system would foster the development of the Italian capital market and help to maintain adequate replacement rates - reduced generosity of the PAYG pillar notwithstanding.

The NDC system was introduced without it being preceded by an extensive debate about its merits and usefulness. Relatively little preparatory work was carried out, no major report was released to the public and the pension formula was not immediately published. Perhaps also because of this, the reform had some major weaknesses (Franco and Sartor, 2006). Most notably, it envisaged a long and complex transition period: only those who started working after 1995 came fully under the new regime.

2 As it is well known, Sweden and Italy were the first countries to adopt the system. Chłloń-Domińczak et al. (2012) provide a comparative overview of the early NDC experiments.

3 In the 1995 law, this parameter was set equal to 1.2. 
Furthermore, the minimum retirement age was relatively low (57 years) and the self-equilibrating mechanisms were not fully adequate (Gronchi et al., 2020).

Even though an NDC system improves work incentives, the effects are not automatic. For them to materialise, governments should properly inform the public about pension rules, and policy makers should avoid interfering with them, so that workers can familiarise with the system and perceive their contributions as invested funds. In Italy, little effort was made after the reform to explain the new pension rules to the public, arguably due to the long transition period.

\section{From 1995 to 2011}

Further non-negligible changes were introduced soon after the 1995 reform. First, in 2005, the requirements for qualifying for an old-age pension were tightened. This was done for all workers irrespective of whether they entered the labour market before or after 1995 (fully NDC), de facto eliminating the significant flexibility in choosing when to retire - one of the features of the NDC reform. Second, in 2007 a third 'channel' for retirement was introduced (besides those based on age and on 'seniority', i.e. years of contribution), based on so-called 'quotas', i.e. the sum of age and years of contribution. The minimum quota was set at 95, to be raised to 97 in 2013.

Short- and medium-term budgetary considerations, which were left out of the 1995 reform, became paramount again, not because the pension system was on an unsustainable path (as in 1992), but owing to the need to rein in the overall general government deficit. However, the opportunity to address the weak points of the Italian NDC was not exploited.

In this period, one of the few unambiguously positive developments was the improvement of the institutional framework of the supplementary funded pillar. Since 2005 , the rules have been streamlined and clarified, the guidelines for pension funds have been harmonised and a new regulatory agency (COVIP) has been created.

\section{The 2011 reform}

The main weakness of the 1995 reform, i.e. its extremely long phase-in period, was finally tackled as the economic and financial crisis was looming. First, in 2010 the government decided that the age requirement to qualify for an old-age pension should move in line with the development of life expectancy. With the 2012 budget, this longevity link was extended to the contributory requirements for a seniority pension. Most importantly, the same law extended the NDC rules for benefit computation pro rata to all workers, starting from 2012. Furthermore, some flex- ibility with regards to retirement was reintroduced for fully NDC workers, up to a maximum of three years before the 'normal' old-age requirement (provided the benefit was at least 2.8 times the social pension).

Concerning non-NDC workers, the 2011 reform eliminated the 'quotas' and further tightened the contributory requirements for seniority pensions.

For all workers, the age requirement for old-age pensions was raised and was fully harmonised irrespective of the activity sector (public or private) or gender. In 2019, the standard age for receiving an old-age pension was 67 years for everyone.

\section{Recent changes}

The rapid tightening of the eligibility criteria for retirement went into effect in 2012 in a difficult macroeconomic context and brought about severe social tensions. The retirement plans of many workers were disrupted. As a reaction, once the most acute phase of the financial crisis was over, a new wave of pension changes were implemented to allow some groups of workers to retire earlier. In 2017, the so-called Anticipo pensionistico sociale (APE) was introduced: workers older than 62 years of age and with at least 30 years of contribution were given the opportunity to retire provided they were unemployed, in poor health or acting as a care-giver for a disabled relative. In 2019, 'quotas' were reintroduced for the next three years, albeit with a more stringent requirement (equal to 100). ${ }^{4}$

While it is too early to assess these recent legislative changes, some comments are in order. First, while both interventions targeted pre-1995 workers, they catered to very different constituencies: the APE supported disadvantaged workers, whereas 'quota 100' mostly targeted workers with relatively long and uninterrupted careers (mainly in the public sector or in large companies based in Northern Italy). Second, neither APE nor quota 100 change what is arguably the main element of the 2011 package, namely the application of the NDC computing principle (albeit pro rata) to all pensions.

\section{A look at the outcomes}

\section{The labour market}

Italy's labour market trends appear in line with the objectives of the reforms. The employment rate for men aged 55 to 64 has increased by almost 23 percentage points in the last 20 years, reducing the gap with respect to the rest of the euro

4 Individuals are required to be at least 62 years of age and have at least 38 years of contributions. The scheme applies until 2021. 
Figure 1

Employment rates of workers aged 55 to 64, Italy and euro area

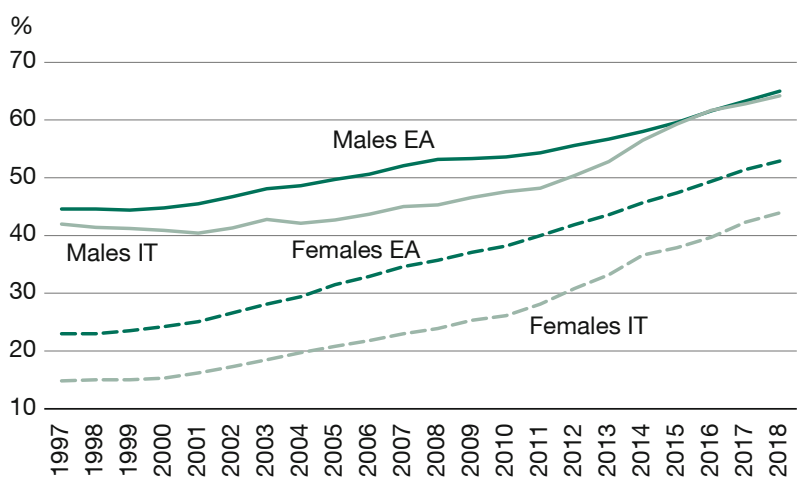

Source: Eurostat, 2020.

area (Figure 1). For women, the increase was even larger almost 29 percentage points - though the gap with the other European countries remains unchanged. Furthermore, there seems to be no negative impact on the employment rate of workers aged 20 to 54 , which in the same period has increased by about four percentage points. This performance is all the more remarkable given the unsatisfactory macroeconomic performance of the country during this time. ${ }^{5}$

5 The idea that in the medium-to-long run there is a trade-off between the employment of relatively younger workers and that of older workers is not backed by the data. See e.g. Tommasino and Zizza (2015) and the literature they cite. Of course, things may be different in the short-run and/or in adverse cyclical conditions (Boeri et al., 2017). More research is needed to understand the effects of higher senior employment on the wages of the young.

\section{Spending pressures}

According to the most recent projections by the European Commission (European Commission, 2018), in Italy public pension outlays as a share of GDP will grow by about three percentage points until about 2040 and will decline steadily thereafter. They are expected to return to the 2016 level in 2060 and to be 1.7 percentage points lower than today in 2070 (Figure 2). By comparison, in the euro area pension expenditure is forecast to increase by 1.2 points by 2040 and to return to the 2016 level in 2060 and slightly below that in 2070 .

During the projection period, the Commission expects Italy's potential GDP to grow by a yearly $0.8 \%$ on average, slower than the euro area average (1.3\%). The fertility rate is expected to increase slightly, from 1.33 children per woman to 1.66, while life expectancy at birth is projected to rise from 80.7 to 86.9 years for men and from 85.3 to 90.9 for women. As a result, the old-age dependency ratio (the ratio of people over 65 to the working age population) is expected to almost double to $60.3 \%$ (Figure 3). In 2070, the only euro area countries with a dependency ratio higher than Italy's would be Greece, Cyprus and Portugal.

\section{Pension adequacy}

The reforms did not reduce the ability of the Italian pension system to ensure decent living standards for most elderly people (Franco et al., 2008). The risk-of-poverty rate among pensioners is currently $15 \%$, similar to the

Figure 2

Change in public pension expenditure 2016-2070, EU countries

percentage points of GDP

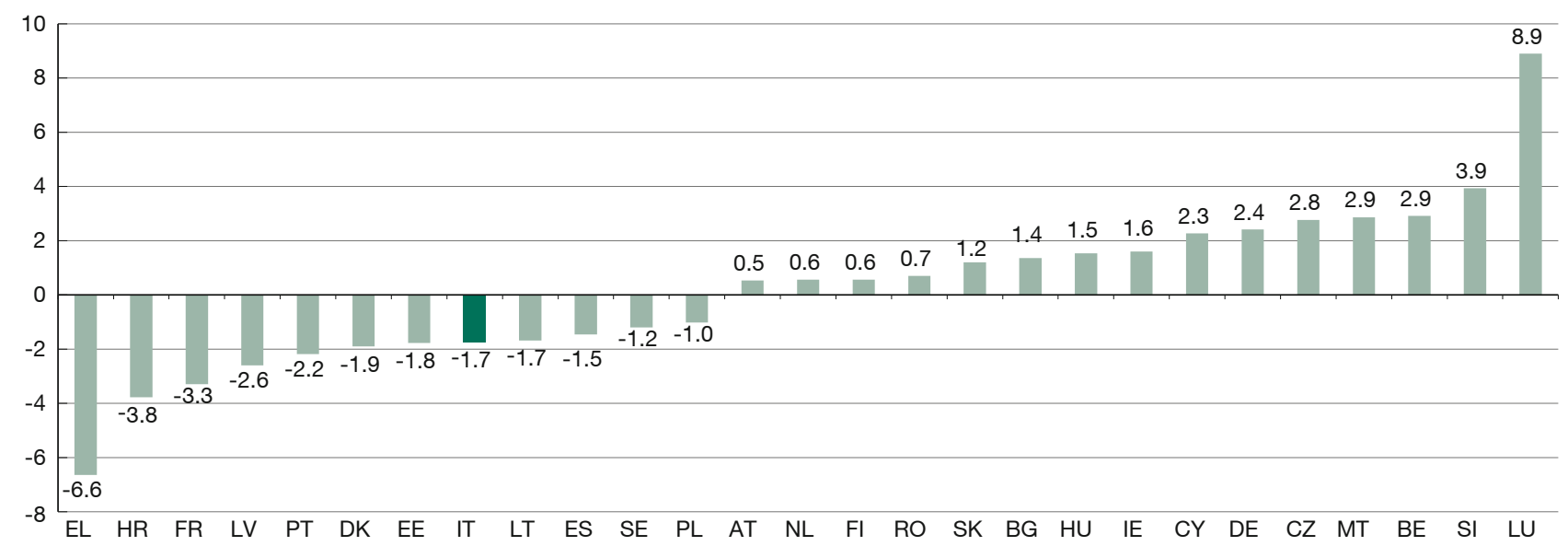

Source: European Commission (2018), The 2018 Ageing Report: Economic and Budgetary Projections for the EU Member States, Brussels. 
Figure 3

Change in the old-age dependency ratio 2016-2070, EU countries

percentage points

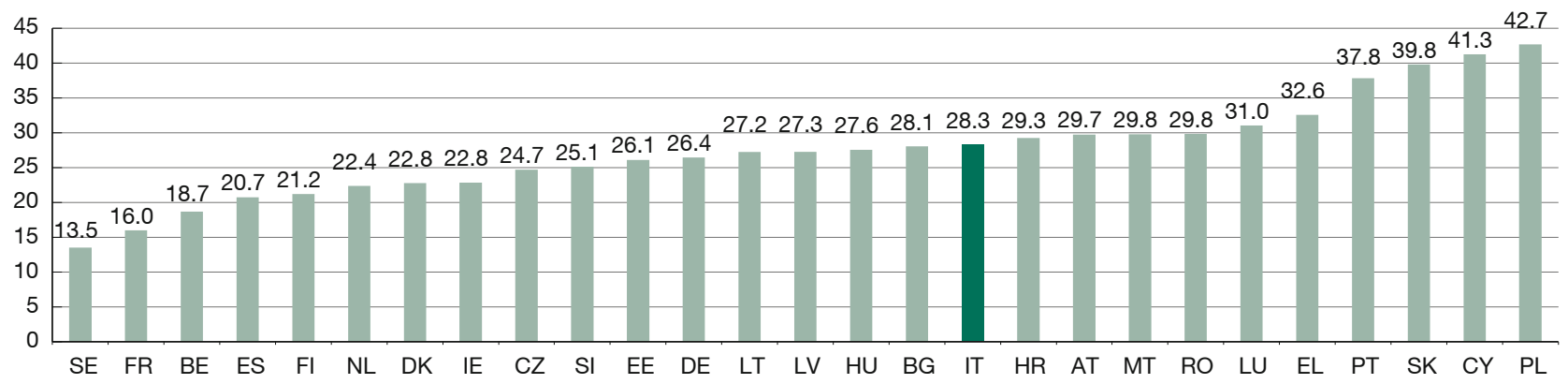

Source: European Commission (2018), The 2018 Ageing Report: Economic and Budgetary Projections for the EU Member States, Brussels.

euro area average rate $(16 \%)^{6}$ and significantly lower than the risk of poverty for the total Italian population (20\%). In Italy, the incidence of absolute poverty among individuals aged 65 or older is $4.6 \%$ and has been quite stable over time (it was $4.4 \%$ in 2007 ); the absolute poverty rate for the whole population is $8.4 \%$, about five percentage points higher than in 2007 - the last year before the economic crisis (Figure 4). ${ }^{7}$

Furthermore, the Italian replacement rate (the ratio of the last wage to the first pension payment) remains among the highest in Europe (Figure 5).

Development of a multi-pillar system

One of the main aims of the reforms was the development of a significant funded pillar. The NDC scheme and the pension funds are subject to different risks and returns. PAYG schemes insure against inflation and financial market risks. However, they are vulnerable to declines in employment, as well as to political risks (governments may 'default' on their promises). Funded schemes are vulnerable to investment risk, but their returns (while more volatile) tend to exceed those of PAYG systems in the long

6 The risk-of-poverty threshold is set at $60 \%$ of the national median equivalised disposable income. The risk-of-poverty rate for pensioners is quite similar to that for elderly people (65+), both in Italy and in the euro area as a whole. The overall risk-of-poverty rate in the euro area is $17 \%$.

7 The data are from the Italian National Institute of Statistics (Istat). A household is considered poor in absolute terms if its consumption expenditure is lower than the monetary value of a basket of goods and services considered "essential". The monetary value of the basket varies in turn according to household socio-demographic characteristics, geographical area and municipality size. The adverse effects of the downturn on living conditions appear milder when looking at the relative poverty indicators because, by construction, their thresholds are set in terms of the average income, which was also dented by the crisis. term (see Feldstein and Ranguelova, 2001). These different features make it advisable to opt for a mixed system, exploiting the portfolio-diversification logic (Lindbeck and Persson, 2003).

As of the end of 2018, about 7.9 million workers $(30.2 \%$ of the work force) were enrolled in supplementary schemes. Pension funds' assets were equal to $9.5 \%$ of GDP, or $4 \%$ of Italian households' financial wealth (Figure 6). Enrolment rates are gradually rising but are still limited among the self-employed, women, small firms' employees, young people and people in Southern Italy. In evaluating these results, one should consider the very large size of the PAYG scheme and the unsatisfactory performance of Italian wages in recent years. There is ample room for progress.

Figure 4

Absolute poverty rate in Italy, 2005-2018

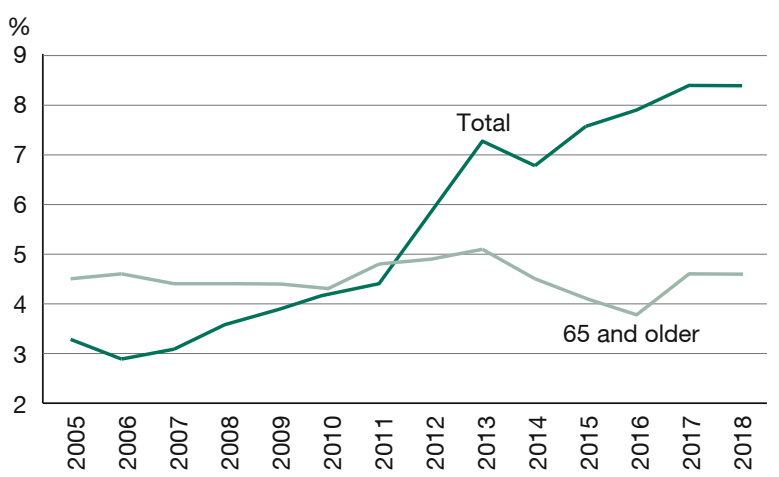

Source: Istat, 2020. 
Figure 5

Gross replacement rates at retirement in the euro area, 2007 and 2018

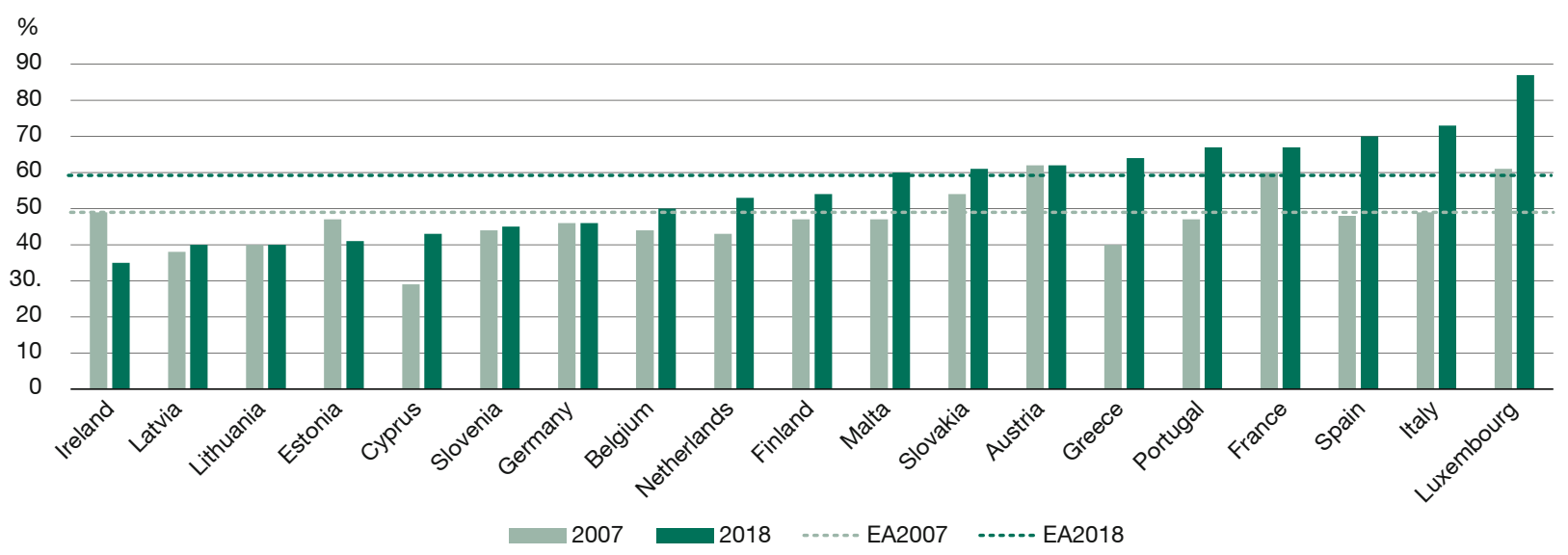

Note: Gross replacement rate is calculated as the ratio of the last wage to the first pension payment.

Source: Eurostat, 2020.

The debate on the pension system and social policy priorities

The advantages of an NDC approach appear stronger than ever. First, increasing workers' mobility across sectors and regions should be a priority in the euro area, given the currently fragmented labour markets and the lack of alternative shock absorption mechanisms. As we know, NDC systems are particularly well suited to accommodate mobile careers and ensure full portability of pension rights. Second, life expectancy and macroeconomic developments have proved very difficult to forecast. NDC systems are robust in the face of unexpected changes in these parameters thanks to their built-in stabilisation mechanisms. Third, in ageing countries there is a need to increase the employment rate significantly. As NDC

Figure 6

Development of the funded pillar in Italy

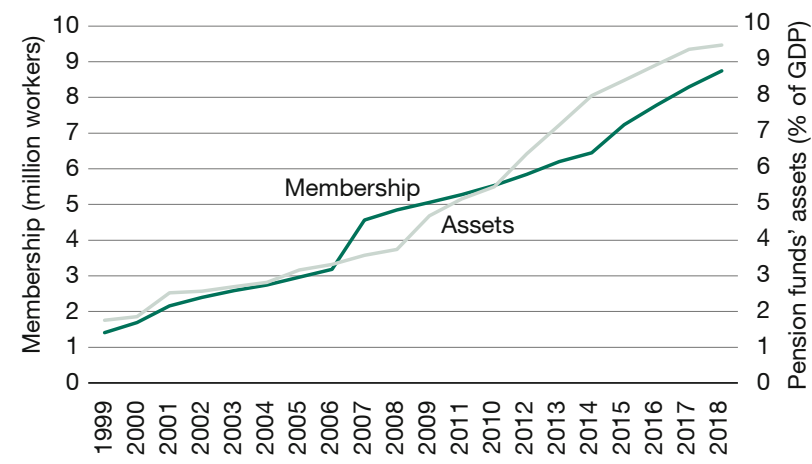

Source: COVIP, 2020. systems tightly link the size of the pension benefit to the amount of contributions paid, they minimise the incentives for early retirement, allowing at the same time some flexibility in setting minimum age requirements.

It would have been preferable to implement from the outset a full NDC regime for all groups and cohorts of workers, but in the end Italy has a sustainable and homogeneous pension system providing appropriate incentives.

This notwithstanding, the Italian NDC system currently faces some challenges. Some of the concerns raised in the policy debate can be accommodated without jeopardising the NDC logic.

The first challenge is about flexibility. In a well-designed NDC scheme, minimum and standard retirement ages have no structural impact on financial sustainability. While in the short term, solutions are constrained by the need to limit expenditure growth (and the general government deficit), flexibility in the Italian system can and should be increased, relying on the fair nature of the system. Fully NDC workers, who will start retiring in large numbers in the upcoming decade, already have a flexible retirement age requirement (starting from age 64). ${ }^{8}$ Regarding pre1995 workers, some flexibility could still be provided after the expiration of quota 100 , but this should be done within the framework of old-age pension rules, as it happens for fully NDC workers.

8 A point worth discussing is whether to modify the income limits for normal retirement (1.5 times the social pension) and for early retirement ( 2.8 times the social pension). 
Another challenge is the differences in life expectancy at retirement. In particular, all other things being equal, if there is a correlation between longevity and lifetime income, the poorer groups of the population end up subsidising the rich. However, this is not exclusive to NDC systems. Actually, NDC systems offer the most straightforward and transparent way out of this issue, by means of group-specific transformation coefficients. ${ }^{9}$

A more fundamental criticism of NDC systems is that they do not redistribute income across pensioners. Indeed, an NDC scheme cannot guarantee a minimum pension income. The old Italian PAYG system, on the contrary, included a minimum contributory pension provision (integrazione al minimo). A lack of within-cohort redistribution has both fairness and efficiency consequences.

From an efficiency perspective, the existence of a meanstested non-contributory pension (such as the assegno sociale) implies that workers with low wages or less than full careers - and therefore with relatively poor contributory pensions - receive low (or even zero) returns on their contributions. While this problem is highly visible in NDC pension schemes, it applies to any form of earnings-related pension. This issue can be addressed by making the phase-out of the non-contributory basic pension more gradual (currently, the assegno sociale decreases one-toone as a function of the pensioner's income; Marano et al., 2012). Furthermore, contribution rates for 'non-standard' workers (self-employed, part-time and temporary workers) should be aligned to those of standard workers (OECD 2019a). In Italy, the 2011 reform narrowed the gap between the contribution rate for standard employees (33\%) and self-employed workers (24\%), but this gap is still wide.

From a normative perspective, while there are compelling reasons to ask for a redistributive, progressive welfare state, this does not mean that every piece of the welfare state should be redistributive. The importance of looking at the welfare system as a whole is particularly relevant for Italy, which has recently introduced a generous meanstested welfare tool (reddito di cittadinanza).

More generally, reform efforts should focus on the social policies 'surrounding' the pension system. Most importantly, while NDC pension rules limit unwarranted incentives to early retirement, appropriate labour market policies are crucial to ensure that the increase in the labour supply of older workers is met by adequate demand. As

9 See Holtzmann et al. (2020) for an analysis of the several possible fixes. Incidentally, to the extent that longevity differences are due to other policy imperfections (e.g. differences in access to health care services or unsafe workplaces), it appears that the best solution is not to adjust the pension rules, but to address the original problem. a matter of fact, an age mix of the labour force that is optimal at the firm level may not be optimal from a social welfare standpoint. Firms often rely on deferred-compensation schemes (such as seniority-based wage ladders; Frimmel et al., 2018) and incur non-negligible fixed costs for hiring and firm-specific training; all other things being equal, these factors make older workers relatively less attractive for employers (Allen, 2019). To address this issue, it may be advisable for governments to subsidise the cost of retaining or hiring older workers (OECD, 2019b) and to promote the inclusion of age management strategies in collective bargaining agreements.

On top of this, it may well be that the general skills and human capital of younger workers are better than those of older workers. ${ }^{10}$ This clearly warrants a public effort to guarantee an adequate amount of (re)training for senior workers. This is currently far from being the case. According to the OECD (2019b), the fraction of older workers having access to training is less than $10 \%$ in Italy, whereas it is about $13 \%$ in France, $18 \%$ in Spain and almost 30\% in Germany (Figure 7).

Italy should also put more effort into improving its education system, which currently lags behind those of other major advanced economies (see Sestito, 2014). A better educated work force is indeed not only less exposed to human capital obsolescence but also easier to retrain later in life.

\section{Conclusions}

Public policies in advanced economies should target different needs. Welfare policies should focus on preventing poverty; progressive taxation and the provision of highquality public services should concentrate on reducing inequalities; labour market policies should aim to create fair wage employment opportunities (including for older workers) and facilitating job-to-job transitions.

Contribution-based pension systems should focus on transferring workers' income across time and insuring against longevity risk in an efficient and transparent way, without the costs and the risks connected with financial markets (which, incidentally, are higher for poor people). This goal should be achieved without exacerbating existing inequalities and without distorting the incentives to work and save. In the context of an ageing population, if one wants to preserve financial stability while guaranteeing acceptable replacement ratios, a longer working life combined with more diversified income for pensioners is necessary. Along these dimensions, well-designed NDC schemes are suitable solutions.

10 According to recent research, this problem might be overstated (Acemoglu and Restrepo, 2019). 
Figure 7

Participation in job-related training

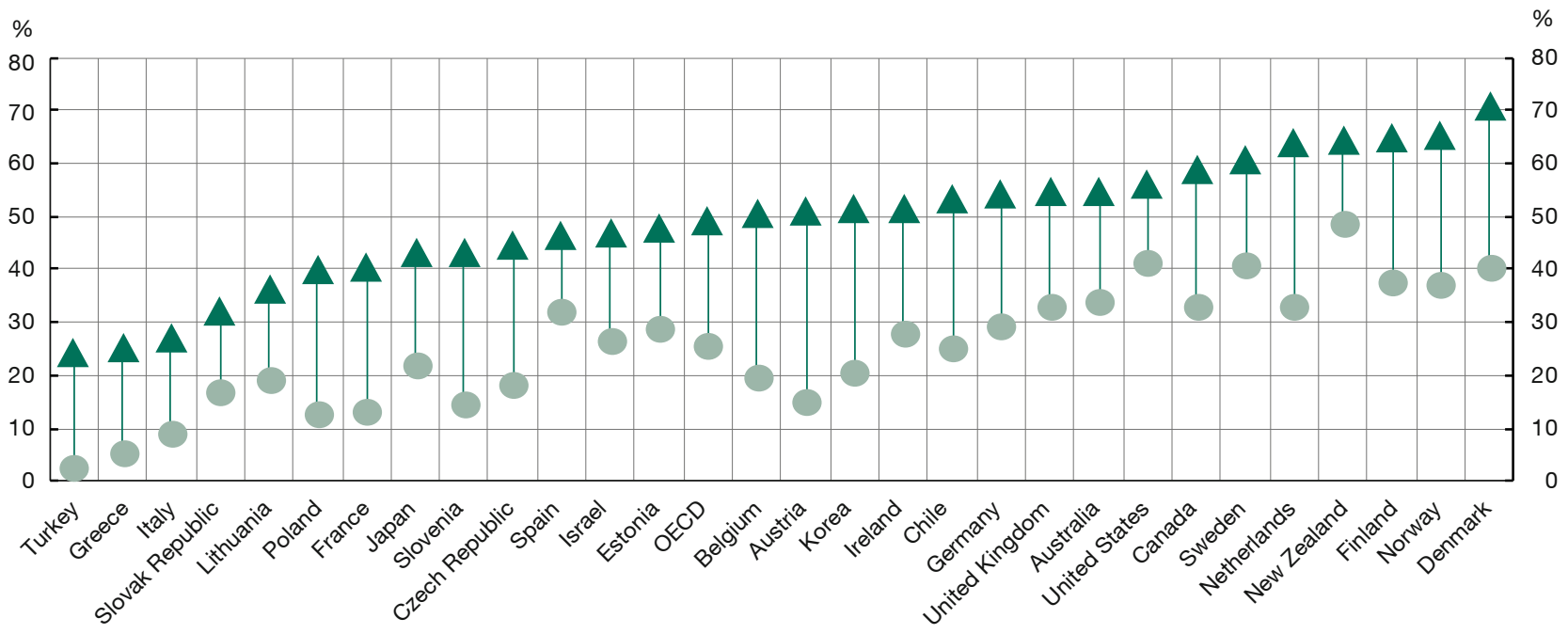

Older adults (55-64) participation

A Younger adults (25-34) participation

Source: OECD (2019), Working better with age, OECD Publishing.

Concerning Italy, this implies that no further broad pension reform - or counter-reform - is needed. Following the many reforms introduced since 1992, a certain degree of stability in legislation is highly desirable: as already noted, in order to reap the full benefits of the current system, people should perceive that the returns on their contributions are reasonably predictable and safe from political risk. Furthermore, one cannot ignore that in the next decade, during which the transition from the mixed system to the NDC will be de facto completed, pension expenditure is set to increase from already high levels. Given the current lack of fiscal space, this should advise against introducing more generous rules in the next few years (Andrle et al., 2018). Italy should instead improve the design of non-pension welfare benefits and the effectiveness of active labour market policies, in both cases targeting elderly workers in particular.

On the contrary, fundamental changes to the basic rules of the system are sometimes proposed in the policy debate. In part, this may be due to the circumstance that, unlike other countries, the introduction of an NDC system in Italy came without an extensive debate about its merits and usefulness; its principles are still not well understood. This is problematic because outcomes in an NDC pension system are sensitive to workers' choices before and at retirement and depend on more parameters than those included in the standard defined-benefits pension formula. In Sweden, since the year after the NDC system was approved, workers have regularly been notified by mail about their pension position (so-called 'orange envelope'). A similar programme was finally launched in
Italy in 2015. Almost all Italian private sector workers are now able - by logging on to the National Social Security Institute (INPS) website - to look at different projections of their final pension treatment based on different macroeconomic scenarios, individual salary progressions and years of retirement. As of May 2018, three million users took the opportunity to use this online tool (Boeri et al., 2020). Over time, this should improve individual decisionmaking (Liebman and Luttmer, 2015; Dolls et al., 2018) and increase support for the current system (Fornero and Lo Prete, 2018; Boeri and Tabellini, 2012).

\section{References}

Acemoglu, D. and P. Restrepo (2018), Demographics and Automation, NBER Working Paper Series, No. 24421.

Allen, S. G. (2019), Demand for Older Workers: What Do Economists Think? What Are Firms Doing?, NBER Working Paper Series, No. 26597. Andrle, M., S. Hebous, A. Kangur and M. Raissi (2018), Italy: Toward a Growth-Friendly Fiscal Reform, IMF Working Papers, No. 18/59.

Barr, N. and P. A. Diamond (2008), Reforming pensions: Principles and policy choices, Oxford University Press.

Boeri, T. and G. Tabellini (2012), Does information increase political support for pension reform?, Public Choice, 150(1), 327-362.

Boeri, T., P. Garibaldi and E. R. Moen (2017), Closing the Retirement Door and the Lump of Labor, mimeo.

Boeri, T., M. Cozzolino and E. Di Porto (2020), Setting Up a Communication Package for the Italian NDC, in R. Holzmann, E. Palmer, R. Palacios and S. Sacchi (eds.), Progress and Challenges of Nonfinancial Defined Contribution Pension Schemes, World Bank, Washington DC.

Chłoń-Domińczak, A., D. Franco and E. Palmer (2012), The First Wave of NDC Countries-Taking Stock Ten Plus Years Down the Road, in R. Holzmann, E. Palmer, and D. Robalino (eds.), NDC Pension Schemes: Progress and Frontiers in a Changing Pension World, World Bank, Washington, DC. 
Dolls, M., P. Doerrenberg, A. Peichl, and H. Stichnoth (2018), Do retirement savings increase in response to information about retirement and expected pensions?, Journal of Public Economics, 158(C), 168179.

European Commission (2018), The 2018 Ageing Report: Economic and Budgetary Projections for the EU Member States, Brussels.

Feldstein, M. S. and E. Ranguelova (2001), Individual Risk in Investmentbased Social Security Systems, American Economic Review, 91(4), 1116-1125.

Fornero, E. and A. Lo Prete (2019), Voting in the aftermath of a pension reform: the role of financial literacy, Journal of Pension Economics and Finance, 18(1), 1-30.

Francese, M., D. Franco and P. Tommasino (2005), Public Pension Reform in Europe and the USA, in Banca d'Italia, Public Expenditure, Proceedings of the 7th Banca d'Italia Public Finance workshop.

Franco, D. (2002), Italy: A Never-ending Pension Reform, in M. Feldstein and $\mathrm{H}$. Siebert, Social Security Pension Reform in Europe, University of Chicago Press.

Franco, D. and M. R. Marino (2002), The Role of Forecasts in Social Security Policy, Giornale degli economisti e Annali di Economia, 61(2), 215265.

Franco, D. and N. Sartor (2005), Notional Defined Contribution in Italy: Unsatisfactory Present, Uncertain Future, in R. Holzmann and E. Palmer (eds.), Non-Financial Defined Contribution (NDC) Pension Schemes: Concept, Issues, Implementation, Prospects, World Bank, Washington DC.

Franco, D., M. R. Marino and P. Tommasino (2008), Pension Policy and Poverty in Italy: Recent Developments and New Priorities, Giornale degli Economisti e Annali di Economia, 67(2), 119-160.

Frimmel, W., T. Horvath, M. Schnalzenberger and R. Winter-Ebmer (2018), Seniority wages and the role of firms in retirement, Journal of Public Economics, 164(C), 19-32.

Gronchi, S., S. Nisticò and M. Bevilacqua (2020), The Italian NDC Scheme: Evolution and Remaining Potholes, in R. Holzmann, E. Palmer, R. Palacios and S. Sacchi (eds.), Progress and Challenges of Nonfinancial Defined Contribution Pension Schemes, Word Bank, Washington DC.

Holzmann, R., J. Alonso-García, H. Labit-Hardy, and A. M. Villegas (2020), NDC Schemes and Heterogeneity in Longevity: Proposals for Redesign, in R. Holzmann, E. Palmer, R. Palacios and S. Sacchi (eds.), Progress and Challenges of Nonfinancial Defined Contribution Pension Schemes, World Bank, Washington DC.

Holzmann, R. and E. Palmer (eds.) (2005), Non-Financial Defined Contribution (NDC) Pension Schemes: Concept, Issues, Implementation, Prospects, World Bank, Washington DC.

Holzmann, R., E. Palmer and D. Robalino (eds.) (2012), NDC Pension Schemes: Progress and Frontiers in a Changing Pension World, World Bank, Washington DC.

Holzmann, R., E. Palmer, R., Palacios and S. Sacchi (eds.) (2020), Progress and Challenges of Nonfinancial Defined Contribution Pension Schemes, World Bank, Washington DC.

Liebman, J. B. and E. F. P. Luttmer, (2015), Would People Behave Differently If They Better Understood Social Security? Evidence from a Field Experiment, American Economic Journal: Economic Policy, 7(1), 275-299.

Lindbeck, A. and M. Persson (2003), The Gains from Pension Reform, Journal of Economic Literature, 41(1), 74-112.

Marano A., C. Mazzaferro and M. Morciano (2012), The strengths and failures of incentive mechanisms in notional defined contribution pension systems, Giornale degli Economisti e Annali di Economia, 71(1), 33-70.

OECD (2019a), Pensions at a Glance 2019, OECD Publishing.

OECD (2019b), Working better with age, OECD Publishing.

Pino, A. and J. Yermo (2010), The impact of the 2007-2009 crisis on social security and private pension funds: A threat to their financial soundness?, International Social Security Review, 63(2), 5-30.

Sestito, P. (2014), La Scuola imperfetta, II Mulino.

Tommasino, P. and R. Zizza (2015), The Lump of Labour Fallacy: a Reassessment for the Euro area, in European Central Bank, Comparisons and contrasts of the impact of the crisis on euro area labour markets, Occasional Paper Series, No. 159. 